\title{
AC 2010-1066: A COMPARATIVE STUDY OF LAND SURVEYING EDUCATION AT THE UNIVERSITY OF LAGOS AND THE PENNSYLVANIA STATE UNIVERSITY
}

\section{James Olaleye, University of Lagos, Nigeria}

Dr. James Olaleye enrolled on the Surveying Degree program at the University of Lagos, Nigeria in 1976. As a result of his brilliant academic performance, Dr. Olaleye became a shell scholar in 1976 and graduated in 1981 with a first class degree in Surveying. In 1987, he was awarded the prestigious commonwealth scholarship for doctoral studies in Canada. With a brilliant record of graduate work, Dr. Olaleye obtained his Ph.D degree in 1992 from the University of New Brunswick, Canada. He has continued the pursuit of academic excellence through the publications of his research findings in mapping in both national and international Journals. He has authored or co-authored over forty publications. He was awarded the prestigious" Talbart Abrams Medal" by the American Society for Photogrammetry and Remote sensing in recognition of his outstanding Publication in Geoinformatics in 1994. Dr. Olaleye is an Associate Professor in the Department of Surveying \& Geoinformatics, University of Lagos. He is also the immediate past Head of Department. He teaches Digital Mapping

\section{Emmanuel Abiodun, University of Lagos, Nigeria}

Mr. O. E. Abiodun is currently an Assistant Lecturer in the Department of Surveying and Geoinformaticss, University of Lagos. Born in Nigeria in 1970, Mr. Abiodun obtained his National Diploma in Surveying from the Federal Polytechnic, Idah, Nigeria in 1994. The same year, he proceeded to the University of Lagos where he obtained his B.Sc. in Surveying in 1999 and M.Sc. degree in Surveying and Geoinformatics in 2004.

Mr. Abiodun worked briefly as Assistant Manager, GIS Research and Development with Anthony Adeoye and Co. (now AAC Consulting) in 2002. He was appointed Lecturer III in the Department of Surveying and Geoinformatics, Osun State College of Technology, Esa Oke, Nigeria in 2004. From there, he was appointed as Assistant Lecturer in the Department of Surveying and Geoinformatics at the University of Lagos.

Mr. Abiodun emerged as the best graduating student in the Department of Surveying, Federal Polytechnic, Idah in 1994 and the best graduating M.Sc. student, Department of Surveying and Geoinformatics, University of Lagos in 2004. He has many papers to his credit both local and international. He is a member of many professional organizations in Nigeria. He is married with children.

\section{Joseph Olusina, University of Lagos, Nigeria}

Dr. J. O. Olusina is a Senior Lecturer and the current Head of Department of Surveying and Geoinformatics, University of Lagos. He obtained his Ordinary National Diploma in Surveying in 1984 and Higher National Diploma in 1987. He later proceeded to the University of Lagos where he obtained his B.Sc. in Surveying in 1991. In 1995, he obtained his M.Sc. degree in Surveying from the same University. He was awarded a Ph.D degree in Surveying and Geoinformatics of the University of Lagos in 2008.

Dr. J. O. Olusina worked between 1989 and 1997 with the Survey Department of the Federal Government of Nigeria's Ministry of Works and Housing. He later joined Yaba College of Technology, Lagos, as Lecturer II between 1997 and 1998. From there he joined the University of Lagos as Lecturer II in the Department of Surveying and Geoinformatics in 1998.

Dr. Olusina was awarded the best graduating student of Department of Surveying, University of Lagos in 1990 and Federal Government of Nigeria's Scholarship for his M.Sc. in 1995. He is a member of many professional organizations in Nigeria and has many publications to his credit. He is married with children. 


\section{Francis Derby, Pennsylvania State University-Lehman}

Dr. Francis Derby obtained a doctoral degree from the University of Florida in Gainesville, where he specialized in cadastral systems and Geographic Information Systems. He is currently Associate Professor of Surveying and Geographic Information Systems at The Pennsylvania State University. He teaches traditional surveying and mapping courses as well as introductory and advanced courses in Geographic Information Systems, Photogrammtetry, and Remote Sensing His previous work experiences include surveying activities in Africa, England, South America and the Caribbean. He has also worked for the Commonwealth Secretariat of Great Britain, where he served as technical advisor to the government of the Commonwealth of Dominica on infrastructure development. He also consulted for the World Bank on various projects in Peru and Tanzania. Dr. Derby is an active member of the American Congress on Surveying and Mapping, and since 2005 he has served on the Geographic and Land Information Systems (GLIS) Board. $\mathrm{He}$ is also a member of American Society for Photogrammetry and Remote Sensing (ASPRS), and the American Society for Engineering Education (ASEE), He currently serves on the executive of the Minorities in Engineering Division (MIND) of ASEE. 


\title{
A Comparative Study of Land Surveying Education at The University of Lagos and Penn State University
}

\begin{abstract}
Recent efforts in globalization have extended beyond commerce, travel, technology transfer and sporting activities. In higher education, globalization has become a catalyst for world class education, diversity in problem solving methods, and improved international understanding. Many institutions of higher learning in developed countries are forming partnerships with sister institutions in developing countries and conducting collaborative learning and research activities through asynchronous teaching and learning, webinars, as well as faculty and student exchange programs. The success of these collaborations depends on a careful examination of overall program objectives as well as expected outcomes of individual programs.
\end{abstract}

Among other related courses, the curricula in both surveying programs include common courses in land Surveying, geodesy, photogrammetry, remote sensing, law and Geographic Information Systems. In addition, University of Lagos provides cartography, hydrography, finance and management studies.

This paper presents a review of program objectives and course outcomes for the two institutions. It concludes by identifying areas of opportunities with regard to course alignment, undergraduate research opportunities, faculty and student exchange and asynchronous collaborative learning. These opportunities form the basis for future collaboration in teaching and research in support of globalization in higher education.

Introduction

Globalization is influencing, and indeed facilitating, interaction between societies, cultures, businesses, and even politics around the world. The drivers of the globalization process have been recent technological advances such as the Internet, telecommunications and geospatial technologies. These technologies are helping to create geographically dispersed but interconnected communities around the world. Again, the catalysts to these technologies are information management and innovation, both of which are dependent on knowledge. Carnoy ${ }^{2}$ contends that globalization increases the demand for education and since knowledge is the product of education, knowledge is therefore fundamental to globalization. This assertion supports the fact that institutions of higher education have a responsibility to export knowledge outside the geographic boundaries for the benefit of the global community.

In recent years, institutions of higher education, especially in developed countries, are also engaging in globalization by connecting with sister institutions in developing opportunities so as to exchange ideas, explore research opportunities so as to empower graduates to compete globally. It is believed that knowledge development and commercialization of knowledge should 
be among the primary objectives of the $21^{\text {st }}$ century universities. Institutions of higher education embark on international programs for various reasons ranging from a desire to address global issues to a desire to provide exposure for the institution, its faculty and students to the international market.

Whatever the reason for exporting knowledge, internationalization of higher education resources in the form of sisterhoods should be conducted with clear expectations on both sides. It is important to recognize that international collaborations, whether in pursuance of globalization or to enhance the higher education system in a developing country, the exercise should be conducted with clearly defined objectives to ensure the mutual interests and expectations. This exercise will help to identify specific areas within the collaborating institutions to which attention should be focused.

\section{The International Program at Penn State}

For many years, Penn State University has had memoranda of understanding for collaboration with many Universities in African universities and governments. One such agreement is the Alliance for Education Science Engineering and Development in Africa (AESEDA) program. The AESEDA program seeks to explore collaboration between Penn State and stakeholders with regard to education and research. Among other things, the education component of AESEDA's activities focuses on graduate research, faculty and student exchange. It also offers opportunities for undergraduate and graduate students from foreign countries to take courses at Penn State. Through this program, major international collaborative activities in research and teaching have been initiated.

The collaboration between the geomatics program at the University of Lagos (UNILAG) and the surveying engineering program at Penn State University is something that has the potential to be rewarding to both programs. However, to establish the level and scope of the collaboration it was necessary to conduct a comparative evaluation of program objectives and course content. It was believed that the outcomes of the evaluations will help identify any preliminary activities in terms course alignment, available resources faculty and student needs, and thereby provide an insight into the extent and scope of collaboration.

Program objective and course content

The geomatics program at UNILAG was established in 1973 as an undergraduate program. In 1997 its name was changed from surveying to geomatics. Over the years, masters and doctoral level programs have been added. In this evaluation, attention was focused on the baccalaureate degree program only. In Nigeria, the Surveyors' Council of Nigeria (SURCON) is responsible for accreditation of Surveying programs and registration of graduate surveyors while Council for the Registration of Engineers (COREN) is responsible for accreditation of engineering programs and registration of graduate Engineers. The surveying program at the University of Lagos is designed to balance the accreditation requirements with the vision of the institution. The vision of the surveying program at the University of Lagos is to produce professional surveyors who are 
also geoscientists with a sound knowledge of theory and practice of the profession to enable them to provide spatial and other environmental information.

The vision is to produce professional surveyors who are also geoscientists with a sound knowledge of theory and practice of the profession, and have the ability to provide spatial and other environmental information. The curriculum of the geomatics program is reviewed regularly to maintain its competitiveness in view of societal demands and advancing technologies. In recent years, the baccalaureate degree curriculum has been reviewed to include new subject -areas such as computer applications, Geographic Information Systems (GIS), Remote Sensing, Digital Mapping, and Environmental Management. The new curriculum promises to prepare our students, in addition to their traditional roles as surveyors, for a new role also as information managers, environmental and coastal management experts, as well as remote sensing experts. The new program also incorporates the General Studies (GST) courses, which are requirements for undergraduate studies by the university.

One striking difference between the two programs is that the UNILAG program takes five years to complete whereas the Penn State program takes four years. The geomatics program has been designed in conformance with other engineering programs at the university. First year students take the same courses as engineering students in the other departments, including Engineering Mathematics at all levels. Students spend the summer vacations of the second and third years, and the whole of second semester of the forth year on industrial attachments. As part of the degree requirements, each student is also required to undertake an independent research project supervised by a faculty member.

The surveying engineering program at Penn State was started in 1964 as an associate degree program. The baccalaureate degree component was started in 1986 with a vision to provide an educational experience that enriches the lives of Surveying Engineering students by providing them with the necessary discipline-related knowledge and skills so that they are prepared to enhance the surveying profession and protect the health and welfare of the public while expanding the base of knowledge through research and scholarship. Surveying Engineering programs in the United States gain accreditation by meeting the requirements of the Accreditation Board for Engineering and Technology (ABET). The associate degree program is accredited by the Technology Accreditation Commission (TAC) of ABET whiles the baccalaureate program is accredited by the Engineering Accreditation Commission (EAC). Program and course objectives have been designed to address this vision and to meet the requirements for continued accreditation by the appropriate commission. Unlike the UNILAG program, the surveying engineering program takes four years to complete. Both the associate and the baccalaureate degree programs are accredited by the Accreditation Board of Engineering and Technology (ABET).

An evaluation of UNILAG and Penn State Surveying programs

A side-by-side comparison of the program contents at the two institutions is shown in Appendix A. Clearly both programs create student-centered environment which includes providing the necessary educational foundation which will produce an extremely knowledgeable graduate who 
is capable of performing the responsibilities a professional surveyor. The training prepares students from both institutions to successfully take the professional licensing examination in their respective countries.

\section{General overview}

In general, the program contents are identical except that the UNILAG program includes hydrographic surveying which is not included in the Penn State program. However, the Penn State program includes storm water management and land development design, both of which are requirements in the professional licensing examination. Professional licensing examinations in surveying and engineering are governed by the National Council of Examiners for Engineering and Surveying (NCEES). In addition to meeting the professional licensing requirements, the Penn State surveying program has to meet accreditation requirements. For accreditation purposes the program and course outcomes have to be measures and documented. Such documentation should demonstrate that both the program and course objectives are meeting predefined accreditation requirements. Although neither the licensing nor accreditation requirements include a need for graduates to demonstrate an ability to compete in the global market, the changing dynamics of globalization is compelling institutions to explore and provide opportunities for graduates to compete globally.

\section{Major differences}

There are a few significant differences in the program content. Firstly, and the most significant difference is the duration of the programs. Whereas the Penn State, and indeed all baccalaureate degree engineering programs in the United States, takes four years, the UNILAG programs take five years to complete. Secondly, the UNILAG program includes one semester of field practical experience as an integral component of the program. Including the summer holidays, the students have to complete three semesters field practical training in addition to the normal laboratory exercises that are associated with individual courses. Clearly, the UNILAG program contains a lot more hands-on exercises than the Penn State program. Thirdly, student in the UNILAG program do not get exposure to any form of surveying until the second semester. Students at Penn State, on the other hand, get involved with surveying courses in the first semester. The objective is to expose students to the profession as early in their career as possible. Because of the rapidly changing equipment and technology, employers in the United States are more interested in graduates who have the skills to apply the most recent technology and use the most modern technology. As such, the use of modern equipment such as Global Positioning Systems (GPS) units is introduced into the curriculum by the second semester of the first year. Electronic data collectors are introduced in the first semester of the first year. Unlike the Penn State program, the latest technologies are not introduced in the UNILAG program until later in the program. This is mainly because many of the employers in Nigeria are not familiar with the recent technology. Those who are familiar with modern technology are not willing to discard existing surveying equipment just for the sake of technology. They are willing to phase new technology into their businesses over time. As such, UNILAG is compelled to continue 
training students in the use old technology such as analytical and semi-analytical photogrammetry using stereo plotters.

\section{Areas of mutual benefit}

An obviously missing component of both programs is an opportunity for preparing students for international exposure as well as an ability to compete in the global market.

There are various opportunities for collaboration which have the potential to be mutually beneficial to both faculty and students on both institutions. Since UNILAG offers the geomatics program to the doctoral level, there are opportunities for to involve graduate students in graduate research activities involving faculty members a Penn State. Results of such research activities and resulting publications will provide international exposure to the graduate students. Another area will be opportunities for student exchange both graduate and undergraduate levels. There are various options for exchanging students. One choice will be for students do three semesters at Penn State (after the second year at UNILAG and return to complete one semester of industrial attachment and the final year. While at Penn State, the students will be enrolled in the third year courses as well as any elective courses. This opportunity allows students to experience education and teaching methods in a developed country. Penn State students also gain the experience of interacting with their international colleagues. In particular, they get to learn about the culture, the land tenure and cadastral system of a developing country. This experience provides them with the knowledge that is needed to participate in international consultancy in land information management.

Faculty members at both institutions can benefit from aligning courses so that professors from UNILAG get exposed to new tools and technologies in the surveying profession which are readily available at Penn State. They will then be able to modify the courses to include the newer technologies and tools. Faculty members at either institutions can also accept sabbatical appointments to spend some time at sister institutions to conduct research and to experience local surveying activities. Likewise, Penn State faculty member can use the exchange program to learn more about local conditions and to introduce international components into their surveying courses. Specifically, land tenure and cadastral systems in developing countries would be used to supplement the boundary principles courses that are taught in Penn State and other surveying institutions within the United States. Recently, various states in Nigeria have begun developing Geographic Information Systems (GIS) to manage land and related resources. Although the state governors' offices are inviting consultants from outside the country, such advice could have been provided through collaboration between faculty members at both institutions under the AESEDA agreement.

\section{Conclusions}

International collaborations among institutions of higher education, in response to globalization, are here to stay. Just as students in developing countries aspire to continue their education abroad, the universities have a responsibility to advance knowledge by exporting education to developing countries. There is a risk to transpose what works in the developed country into a 
developing country. Such approach has a potential to fail if local conditions and cultures are not considered. In the case of surveying programs between Penn State and UNILAG, a comparative study has highlighted areas where faculty and students from both institutions can benefit form such collaboration. Through the evaluation, it was possible to identify opportunities. Some of the modalities for implementing those opportunities have to be developed through administrative arrangements, logistics, technology, scheduling and other means. The good thing is that it was possible to identify possible failures before they occur.

References:

1. Adewale, O. S. 2002, Surveying and Geomatics Curricula in Nigerian Universities - The Professional and Educational Challenges. FIG International Conference, Washington D.C. April 19 - 26, 2002.

2. Carnoy, M. 2005. Globalization Educational Trends and the Open Society. Open Society Institute Education Conference. Budapest, June 30 - July 3, 2005.

3. Derby, F. W. 2000. Integration of Information Technology into Surveying Courses at Penn State University. Surveying and land Information Systems. Vol. 60, No. 1, pp 55 - 60.

4. Kweik, M. 2001, Globalization and Higher Education. Higher Education in Europe, Vol. XXVI, No.1, 2001. 
Appendix 1: Course offerings in Geomatics at UNILAG and Surveying Engineering at Penn State

\begin{tabular}{|c|c|c|c|c|}
\hline \multicolumn{3}{|c|}{ University of Lagos } & \multicolumn{2}{|r|}{ Penn State Unive } \\
\hline Course & Title & Credits & Course & Title \\
\hline & Year 1 Semester 1 & & & Year 1 semester 1 \\
\hline SVY 101 & History of Surveying & 1 & SUR 111 & Plane Surveying@ \\
\hline EAG 101 & Pure Math I & 3 & MATH 140 & Calculus with Analytical Ge \\
\hline EAG 103 & Applied Math I & 3 & ENGL 015 & Rhetoric and Composition \\
\hline MEG 101 & Workshop Practice & 1 & EDSGN 100 & Engineering Design and Gra \\
\hline MEG 103 & Technical Drawing I & 2 & $\begin{array}{l}\text { GEOG10 or } \\
\text { CHEM110 }\end{array}$ & $\begin{array}{l}\text { Introduction to Physical Geo } \\
\text { Chemical Principles }\end{array}$ \\
\hline FSC 105 & Introductory Physics I & 3 & SUR 100S & Freshman Seminar in Survey \\
\hline GST 103 & Nigerian People \& Culture & 2 & & Total \\
\hline GST 102 & Intro. to Logic and Philosophy & 2 & & \\
\hline GST 105 & Use of English & 1 & & \\
\hline & Total & 18 & & \\
\hline & Year 1 Semester 2 & & & Year 1 Semester 2 \\
\hline SVY 102 & Basic Surveying I & 1 & SUR 112 & Curve Geometry \\
\hline EAG 102 & Pure Math II & 2 & SUR 162 & Methods in Large-Scale Map \\
\hline EAG 104 & Applied Math II & 2 & MATH 141 & Calculus with Analytical Ge \\
\hline MEG 102 & Workshop Practice II & 1 & MATH 220 & Matrices \\
\hline MEG 104 & Technical Drawing II & 2 & GA, GH, GS & $\begin{array}{l}\text { Arts (GA), Humanities (GH) } \\
\text { (GS) }\end{array}$ \\
\hline PHS 101 & Introductory Physics II & 2 & GHA & Health and Activities \\
\hline PHS 102 & Introductory Physics III & 3 & & Total \\
\hline PHS 103 & Lab (Physics) & 2 & & \\
\hline GST 104 & History \& Philosophy of Science & 2 & & \\
\hline GST 106 & Use of English & 2 & & \\
\hline & Total & 18 & & \\
\hline
\end{tabular}

\begin{tabular}{|c|c|c|c|c|}
\hline \multicolumn{3}{|c|}{ University of Lagos } & \multicolumn{2}{|r|}{ Penn State U } \\
\hline Course & Title & Credits & Course & Title \\
\hline & Year 2 Semester 1 & & & Year 2 Semester 1 \\
\hline SVY 201 & Basic Surveying II & 3 & SUR 241 & Surveying Measureme \\
\hline GRY 203 & Cartography & 3 & STAT 401 & Experimental Methods \\
\hline EAG 203 & Engineering Math I & 3 & MATH 230 & Calculus \& Vector An \\
\hline EEG 201 & Fund. of Elect. Engr. I & 3 & GA/GH/GS & Arts, Humanities, \& S \\
\hline PHS 201 & Classical Mechanics I & 2 & ECON 2/4/14 & Social Science (GS) \\
\hline PHS 219 & Practical Physics I & 1 & & Total \\
\hline PHS 261 & Geophysics I & 2 & & \\
\hline GAS 201 & General African Studies I & 2 & & \\
\hline PHS 207 & Optics & 2 & & \\
\hline & Total & 21 & & \\
\hline & & & & \\
\hline & Year 2 Semester 2 & & & Year 2 Semester 2 \\
\hline SVY 202 & Engineering Surveying & 3 & SUR 222 & Photogrammetry \\
\hline EAG 202 & Intro. Engr. Stat. \& Computer System & 3 & SUR 262 & Coordinate Systems \& \\
\hline PHS 208 & Intro. To Astrophysics & 2 & MATH 251 & Differential Equations \\
\hline SVY210 & Photogrammetry I & 3 & PHYS 211 & Mechanics \\
\hline PHS 220 & Practical Physics II & 1 & CMPSC 201C & C Programming for \\
\hline GAS 202 & Gen. African Studies II & 2 & & Total \\
\hline
\end{tabular}




\begin{tabular}{|l|l|l|}
\hline SVY 204 & Remote Sensing I & 3 \\
\hline SVY 206 & Computer Application in Surveying I & 2 \\
\hline & Total & $\mathbf{2 0}$ \\
\hline & & \\
\hline & Elective & \\
\hline PHE 207 & Introduction to Swimming I & 1 \\
\hline
\end{tabular}

\begin{tabular}{|c|c|c|}
\hline \multicolumn{3}{|c|}{ University of Lagos } \\
\hline Course & Title & Credits \\
\hline & Year 3 semester 1 & \\
\hline SVY 305 & Cadastral Surveying I & 3 \\
\hline SVY 307 & Spherical and Field Astronomy & 3 \\
\hline ESM 351 & Applied Town Planning & 2 \\
\hline SVY 309 & Adjustment Comp. I & 3 \\
\hline SVY 311 & Hydrographic Surveying I & 3 \\
\hline SVY 313 & Principles of Geo. Information System I & 3 \\
\hline \multirow[t]{3}{*}{ PHS 301} & Classical Mechanics II & 3 \\
\hline & Total & 20 \\
\hline & Elective & \\
\hline \multirow[t]{2}{*}{ PHE 207} & Introduction to Swimming I & 1 \\
\hline & Year 3 Semester 2 & \\
\hline SVY 302 & Geodetic Surveying & 3 \\
\hline SVY 306 & Cadastral Surveying II & 3 \\
\hline SVY 308 & Geodetic Astronomy & 2 \\
\hline SVY 310 & Electronic Surveying & 3 \\
\hline SVY 312 & Computer Appl. In Surveying II & 3 \\
\hline SVY 314 & Principles of Geo. Information System II & 3 \\
\hline \multirow[t]{2}{*}{ SVY 316} & Digital Mapping I & 2 \\
\hline & Total & 20 \\
\hline \multicolumn{3}{|l|}{ Elective } \\
\hline SVY 300 & Industrial Training & 4 \\
\hline \multicolumn{3}{|c|}{ Plus at least 2 Units of Electives below: } \\
\hline EAG 302 & Operational Methods & 2 \\
\hline PHE 207 & Introduction to Swimming II & 1 \\
\hline CEG 304 & Engineering Geology & 3 \\
\hline
\end{tabular}

\begin{tabular}{|l|l|l|}
\hline \multicolumn{2}{|c|}{ University of Lagos } \\
\hline Course & Title & Credits \\
\hline & Year 4 Semester 1 & \\
\hline SVY 401 & Map Projection & 3 \\
\hline SVY 413 & Photogrammetry and Remote Sensing I & 3 \\
\hline SVY 415 & Geodesy I & 3 \\
\hline SVY 417 & Digital Mapping II & 2 \\
\hline EAG 405 & Engineering Statistics & 2 \\
\hline EAG 403 & Numerical Methods in Engineering & 3 \\
\hline GEG 401 & Tech. Communications & 1 \\
\hline & Total & $\mathbf{1 7}$ \\
\hline Plus at least 5 Units of Electives from below: & \\
\hline SVY 405 & Mining \& Underground Survey & 3 \\
\hline SVY 409 & Potential Theory \& Spherical Harmonics & 2 \\
\hline SVY 411 & Special Surveys & 3 \\
\hline & & \\
\hline
\end{tabular}

\begin{tabular}{|c|c|}
\hline \multicolumn{2}{|r|}{ Penn State Uni } \\
\hline Course & Title \\
\hline & Year 4 Semester 1 \\
\hline SUR 471 & Professional Aspects of \\
\hline SUR 490 & Seminar in Surveying \\
\hline Tech. Elec. & Technical Elective \\
\hline Tech. Elec. & Technical Elective \\
\hline GA, GH, GS & Arts, Humanities, \& So \\
\hline GA, GH, GS & Arts, Humanities, or So \\
\hline & Total \\
\hline & \\
\hline & \\
\hline & \\
\hline & مَّ \\
\hline & (1) \\
\hline & G \\
\hline & $V$ \\
\hline & $\overrightarrow{0}$ \\
\hline
\end{tabular}




\begin{tabular}{|l|l|l|}
\hline & Year 4 Semester 2 & \\
\hline SVY 400 & Industrial Attachment & 8 \\
\hline & & \\
\hline & Year 5 Semester 1 & \\
\hline SVY 501 & Adjustment Comp. II & 3 \\
\hline SVY 505 & Survey Laws and Regulation & 2 \\
\hline GEG 501 & Engineering Economics & 2 \\
\hline SVY 511 & Project & 3 \\
\hline & Total & $\mathbf{1 0}$ \\
\hline & & \\
\hline & & \\
\hline
\end{tabular}

\begin{tabular}{|l|l|}
\hline & \\
\hline & \\
\hline & Year 4 Semester 2 \\
\hline SUR 441 & Data Analysis and Proj \\
\hline SUR 482 & Land Development Des \\
\hline Tech. Elec. & Technical Elective \\
\hline Tech. Elec. & Technical Elective \\
\hline GA, GH, GS & Arts, Humanities, or So \\
\hline H \& A & Health and Activities \\
\hline & Total \\
\hline
\end{tabular}

\begin{tabular}{|c|c|c|}
\hline \multicolumn{3}{|c|}{ University of Lagos } \\
\hline Course & Title & Credits \\
\hline & Year 5 Semester 1 & \\
\hline \multicolumn{3}{|c|}{ Plus at least 7 Units of Electives from below: } \\
\hline SVY 503 & Special Studies in Digital Remote Sensing & 3 \\
\hline SVY 509 & Geometric Geodesy & 3 \\
\hline SVY 517 & Photogrammetry \& Remote Sensing II & 3 \\
\hline SVY 523 & Intro. to Coastal Mapping \& Management & 2 \\
\hline SVY 525 & GIS Tools \& Applications & 3 \\
\hline GEG 503 & Surface Water Hydraulics & 2 \\
\hline GEG 519 & River Engineering & 2 \\
\hline \multirow[t]{2}{*}{ SVY 519} & Mathematical Geodesy & 2 \\
\hline & Year 5 Semester 2 & \\
\hline SVY 502 & Adjustment Computation III & 3 \\
\hline SVY 506 & Prof. practice and Ethics & 3 \\
\hline SVY 512 & Project & 3 \\
\hline \multirow[t]{2}{*}{ GEG 502} & Engineering Law \& Management & 2 \\
\hline & Total & 11 \\
\hline \multicolumn{3}{|c|}{ Plus at least 9 Units of Electives from below: } \\
\hline SVY 510 & Physical Geodesy & 3 \\
\hline SVY 508 & Hydrographic Surveying II & 3 \\
\hline SVY 516 & Marine Surveying & 3 \\
\hline CEG 504 & Ground Water Hydrology & 3 \\
\hline SVY 504 & $\begin{array}{l}\text { Spcl. Studies in Analytical \& Digital } \\
\text { Photogrammetry }\end{array}$ & 3 \\
\hline SVY 513 & Satellite Geodesy & 3 \\
\hline SVY 515 & Applied Geophysics & 2 \\
\hline SVY 528 & Close-Range Photogrammetry & 3 \\
\hline & & \\
\hline & & \\
\hline & & \\
\hline & & \\
\hline & & \\
\hline & & \\
\hline & & \\
\hline & & \\
\hline
\end{tabular}

\begin{tabular}{|c|c|}
\hline & Penn State Uni \\
\hline Course & Title \\
\hline & Technical Elective Co \\
\hline SUR 313 & Practical Field Problem \\
\hline SUR 425 & Advanced Photogramm \\
\hline SUR 455 & Precise Positioning Sys \\
\hline SUR 465 & LIS Applications \\
\hline SUR 285 & Drainage Design \\
\hline SUR 485 & Stormwater Design \\
\hline GEOG 352 & Image Analysis \\
\hline & \\
\hline & \\
\hline & \\
\hline & \\
\hline & \\
\hline & \\
\hline & Additional Elective Co \\
\hline ACCTG 211 & $\begin{array}{l}\text { Financial and Manager } \\
\text { Decision Making }\end{array}$ \\
\hline ACCTG 311 & Accounting Systems an \\
\hline B A 243 & $\begin{array}{l}\text { Social, Legal, and Ethi } \\
\text { Business }\end{array}$ \\
\hline B A 250 & Problems of Small Bus \\
\hline B A 321 & $\begin{array}{l}\text { Contemporary Skills fo } \\
\text { Professionals }\end{array}$ \\
\hline B A 322 & $\begin{array}{l}\text { Individual and Interper } \\
\text { for the Bus. Prof. }\end{array}$ \\
\hline CE 360 & Fluid Mechanics \\
\hline EMCH 11 & Statics \\
\hline EMCH 12 & Dynamics \\
\hline FIN 301 & Corporation Finance \\
\hline IST 210 & Organization of Data \\
\hline IST 211 & $\begin{array}{l}\text { Advanced Topics in Re } \\
\text { Management Systems }\end{array}$ \\
\hline IST 221 & Introduction to Telecon \\
\hline IST 222 & Voice and Data Comm \\
\hline INS 301 & Risks and Insurance \\
\hline MGMT 301 & Basic Managementeor \\
\hline MGMT 341 & Human Resource N西的 \\
\hline
\end{tabular}




\begin{tabular}{|l|l|l|}
\hline & & \\
\hline & & \\
\hline & & \\
\hline & & \\
\hline & \multicolumn{2}{|l|}{} \\
\hline
\end{tabular}

MKTG 301W

R EST 301

SUR 211

SUR 496

SUR 497
Principles of Marketing Real Estate Fundament Construction Surveying Independent Studies Selected Topics in Lan 